\title{
Ultrasound Assisted Synthesis of Polylimonene and Organomodified-clay Nanocomposites: A Structural, Morphological and Thermal Properties
}

\author{
Hodhaifa Derdar ${ }^{1,2, *}$, Geoffrey Robert Mitchell ${ }^{3}$, Zakaria Cherifi ${ }^{1,2}$, Mohammed Belbachir ${ }^{2}$, \\ Mohamed Benachour ${ }^{2}$, Rachid Meghabar ${ }^{2}$, Khaldoun Bachari ${ }^{1}$, Amine Harrane ${ }^{1,4}$ \\ ${ }^{1}$ Centre de Recherche Scientifique et Technique en Analyses Physico-Chimiques (CRAPC), BP 10 384, \\ Siège ex-Pasna Zone Industrielle, Bou-Ismail CP 42004, Tipaza, Algeria. \\ ${ }^{2}$ Laboratoire de Chimie des Polymères, Département de Chimie, Faculté des Sciences Exactes et \\ Appliquées, Université Oran1 Ahmed Benbella, BP 1524, El-Mnaouer, 31000 Oran, Algeria. \\ ${ }^{3}$ Centre for Rapid and Sustainable Product Development, Institute Polytechnic of Leiria, Marinha \\ Grande, Portugal. \\ ${ }^{4}$ Department of Chemistry, FSEI, University of Abdelhamid Ibn Badis Mostaganem, Algeria.
}

Received: 15th October 2020; Revised: 22nd October 2020; Accepted: 23rd October 2020; Available online: $9^{\text {th }}$ November 2020; Published regularly: December 2020

\section{Abstract}

Polylimonene-clay nanocomposites (PLM-Mag 2, 3, 6 and $10 \%$ by weight of clay) were prepared by mixing Maghnite-CTA ${ }^{+}\left(\mathrm{Mag}_{-} \mathrm{CTA}^{+}\right)$and polylimonene (PLM) in solution using ultrasonic irradiation. The catalyst preparation method were studied in order to determine and evaluate their structural, morphological and thermal properties. The Mag-CTA ${ }^{+}$is an organophylic montmorillonite silicate clay prepared through a direct exchange process, using green natural clay of Maghnia (west of Algeria) called Maghnite. The Algerian clay was modified by ultrasonic-assisted method using cetyltrimethylammonuim bromide (CTAB) in which they used as green nano-reinforcing filler. Polylimonene was obtained by the polymerization of limonene, using $\mathrm{Mag}-\mathrm{H}^{+}$as a catalyst. The morphology of the obtained nanocomposites was studied by X-ray diffraction (XRD), scanning electronic microscopy (SEM), transmission electronic microscopy (TEM) and infrared spectroscopy (FT-IR). Thermogravimetric analysis (TGA) shows that the nanocomposites have a high degradation temperature $\left(200-250{ }^{\circ} \mathrm{C}\right) \mathrm{com}$ pared with the pure polylimonene $\left(140^{\circ} \mathrm{C}\right)$. The analyses confirmed the chemical modification of montmorillonite layers and their uniformly dispersion in the polylimonene matrix. Exfoliated structures were obtained for low amounts of clay ( 2 and $3 \%$ by weight), while intercalated structures and immiscible regions were detected for high amounts of clay ( 6 and 10\% by weight). Copyright (C) 2020 BCREC Group. All rights reserved

Keywords: Ultrasound; Polylimonene; Nanocomposites; Organo-modified clay; Polymer/clay

How to Cite: Derdar, H., Mitchell, G.R., Cherifi, Z., Belbachir, M., Benachour, M., Meghabar, R., Bachari, K., Harrane, A. (2020). Ultrasound Assisted Synthesis of Polylimonene and Organomodifiedclay Nanocomposites: A Structural, Morphological and Thermal Properties. Bulletin of Chemical Reaction Engineering \& Catalysis, 15(3), 798-807 (doi:10.9767/bcrec.15.3.9185.798-807)

Permalink/DOI: https://doi.org/10.9767/bcrec.15.3.9185.798-807

\section{Introduction}

In the last decades, a growing interest is fo-

* Corresponding Author.

Email: hodhaifa-27@outlook.fr (H. Derdar) cused on a new class of materials, reinforced by nanoscale particles, called nanocomposites. Interest in these new materials was initiated by Toyota researchers in the early 1990s. In fact, by dispersing clays in polyamide- 6 by in situ 
polymerization, they showed a significant increase in dimensional stability [1]. These results have been the precursor to new perspectives for polymer matrix nanocomposites in many scientific fields [2]. In recent years, nanocomposites based on toxic polymers have been replaced by others based on green materials. The use of a polymer matrix by adding a welldefined percentage of clay as reinforcement leads to the improvement of the physicochemical properties of the resulting nanocomposites such as high modulus, increased heat resistance, adhesion and barrier gas properties, flammability, and increased biodegradability of biodegradable polymers [3,4]. Based on the interaction strength of the modified polymer/clay, two different types of nanocomposites structures can be synthesized, intercalated and exfoliated nanocomposites. The synthesis of nanocomposites can be done by different methods such as in-situ polymerization, solution blending of polymer and other methods [5].

Limonene is a monocyclic terpene found in many essential oils extracted from citrus zest [6]. The first polymerization of terpenes was carried out in 1798, when Bishop Watson added a drop of sulfuric acid to produce a sticky resin [7]. The copolymerization of limonene with other monomers, such as: styrene was also attempted using azobisisobutyronitrile (AIBN) as a radical catalyst [8]. However, at that time, the researchers could not distinguish the interesting properties of this material, which further delayed its 50 year study. In 1950, William Roberts studied the cationic polymerization of many terpenes such as limonene, $\alpha$-pinene and $\beta$-pinene with Friedel-Crafts catalysts, for example $\mathrm{SnCl}_{4}$ and $\mathrm{AlBr}_{3}$ [9]. By adding less than $1 \%$ of catalyst in toluene, William Roberts produces a solid $\beta$-pinene polymer with a low molecular weight of about $1500 \mathrm{~g} / \mathrm{mol}$. The degree of polymerization of $\beta$-pinene, although very low, is higher than that of the two other monomers (limonene, $\alpha$-pinene) [10,11]. Limonene has been widely used in a wide range of products such as cosmetics, as food additives, medicine and even as a green solvent [12].

The use of ultrasound for the preparation of nanocomposites based on polymer and clay in solution is very interesting. This method of synthesis was used to reduce the reaction time and also to increase the dispersion of nano-fillers in polymer matrix with most of them focusing to exfoliate the packed layers of clay [13-17]. The ultrasonification induces acoustic stream and cavitation bubbles that subsequently undergo an implosion process resulting in a consequent release of heat and energy leading afterwards a highly well dispersed reaction medium [18], the use of ultrasound has also an impact on the morphology of the prepared nanocomposites especially in dispersion like in-situ polymerization methods [19]. For these reasons, several nanocomposites based on polymers and clay was prepared under ultrasound-assisted method.

By examining the literature, we find that the use of natural clay as nanorenfort in the synthesis of green-nanocomposites based on polylimonene and clay is practically nonexistent. The main goal of this work is to use an organo-modified montmorillonite clay called Maghnite-CTA ${ }^{+}\left(\mathrm{Mag}_{-} \mathrm{CTA}^{+}\right)$as a new nanoreinforcing filler in order to improve both thermal and mechanical properties of polylimonene, also, to prepare green-nanocomposites out of green raw materials (limonene and clay). In previously published work, we have shown the advantage of applying this type of nanorenfort in several nanocomposites synthesis [20]. It is preferred for its many advantages such as a very low purchase price compared to other nano-reinforcing fillers.

\section{Materials and Methods}

\subsection{Materials}

In this work we have used (R)-(+)-Limonene (97\%), methanol $\left(\mathrm{CH}_{3} \mathrm{OH}, 99.9 \%\right)$, Dichloromethane $\left(\mathrm{CH}_{2} \mathrm{Cl}_{2}, \quad 99.8 \%\right)$, cetyltrimethylammonuim bromide (CTAB), sodium chloride $(\mathrm{NaCl})$ and sulphiric acid $\left(\mathrm{H}_{2} \mathrm{SO}_{4}\right)$ are supplied by Sigma Aldrich and used as received. Maghnite (Algerian montmorillonite) is supplied in the raw state by ENOF Bental Spa of the National Company of Nonferrous Mining Products, Maghnia Unit (Algeria). The ultrasound instrument used for the preparation of Mag- $\mathrm{CTA}^{+}$and nanocomposites consists of a jacketed glass vessel provided with ultrasonic horn (13.6 mm diameter made of Titanium alloy Ti-6Al-4V non-replaceable tip) equipped with a Sonics VC-750 Vibra6 Cell generator.

\subsection{Characterizations of Catalyst}

XRD diffraction patterns using Bruker AXS $\mathrm{D} 8$ diffractometer $(\mathrm{Cu}-\mathrm{K} \alpha$ radiation). The functional groups of the modified clay and its nanocomposites were analyzed by infrared spectroscopy FT-IR in the range of $4000-360 \mathrm{~cm}^{-1}$ using BRUKER ALPHA Diamond-ATR. Molar Masses of polylimonene were studied by SEC analyses using a GPC-PL120 apparatus, $\mathrm{CH}_{2} \mathrm{Cl}_{2}(1.0 \mathrm{~mL} / \mathrm{min})$ as the mobile phase at 
$27.5{ }^{\circ} \mathrm{C}$ and Polystyrene standards were used for column calibration. Thermal properties were analyzed by thermogravimetric analysis (TGA) using PerkinElmer STA 6000 under air and nitrogen in the temperature range 30-700 ${ }^{\circ} \mathrm{C}$ with a heating rate of $20{ }^{\circ} \mathrm{C} / \mathrm{min}$. The surface morphology of the modified clay and its nanocomposites were observed by FEG-SEM on a, JEOL 7001F electron microscopy and Transmission electron micrographs were performed on a Hitachi 8100 .

\subsection{Preparation of Maghnite- $\mathrm{H}^{+}\left(\right.$Mag- $\left.\mathrm{H}^{+}\right)$}

Mag- $\mathrm{H}^{+}$is prepared according to the process reported in our previous study [21,22]. Mag- $\mathrm{H}^{+}$ is activated with a sulfuric acid solution to give a Maghnite exchanged with protons. In an Erlenmeyer flask, crushed raw-Mag (20 g) is dispersed in a volume of distilled water $(120 \mathrm{~mL})$. The mixture is stirred $2 \mathrm{~h}$ at room temperature. Then, a solution of sulfuric acid $(0.25 \mathrm{M})$ is added. The solution thus obtained is maintained for two days under stirring. The mineral is filtered off and washed several times with distilled water up to $\mathrm{pH}$ 7. After filtration, Mag- $\mathrm{H}^{+}$is dried in an oven for $24 \mathrm{~h}$, at $105{ }^{\circ} \mathrm{C}$ and then crushed. Its structure is established by FT-IR and XRD.

Table 1. Effect of the amount of Mag- $\mathrm{H}^{+}$on the Mn of PLM.

\begin{tabular}{cc}
\hline Mag- $\mathrm{H}^{+}(\mathrm{wt} \%)$ & $\mathrm{Mn}(\mathrm{g} / \mathrm{mol})$ \\
\hline 2 & 360 \\
4 & 513 \\
5 & 625 \\
10 & 1360 \\
15 & 1320 \\
20 & 1290 \\
25 & 1192 \\
\hline
\end{tabular}

\subsection{Preparation of Mag- $\mathrm{Na}^{+}$and Mag-CTA ${ }^{+}$}

Mag- $\mathrm{Na}^{+}$was prepared according to the protocol described by Belbachir et al. [23]. The raw-Mag supplied by Bental Spa, is crushed and finely sieved, the activation of Maghnite by sodium was carried out using $1 \mathrm{~L}$ of $\mathrm{NaCl}$ solution ( $1 \mathrm{M})$ and $20 \mathrm{~g}$ of raw-Mag ( $2 \%$ by weight), the latter is mixed for $24 \mathrm{~h}$ at room temperature, finally the Maghnite was washed several times with distilled water.

The Mag-CTA ${ }^{+}$activation were carried out by ultrasound during $1 \mathrm{~h}$ [19]. Firstly $10 \mathrm{~g}$ of Mag- $\mathrm{Na}^{+}$is placed in a $1 \mathrm{~L}$ Erlenmeyer flask with the chosen concentration (1 CEC). At the end of the exchange process, the suspension is filtered and then washed several times with distilled water. Finally the solid obtained is dried at $105{ }^{\circ} \mathrm{C}$ during $24 \mathrm{~h}$ and ground. The structure of organophylic clay is confirmed by FT-IR and XRD analysis and their morphological properties are studied by SEM and TEM analysis.

\subsection{Synthesis of Polylimonene (PLM)}

The polymerization of limonene is carried out according to the protocol described by Derdar et al. [24], in solution and in bulk using Mag- $\mathrm{H}^{+}$as catalyst. In a flask containing $2 \mathrm{~g}$ $(0.01 \mathrm{~mol})$ of limonene, we added an amount of $10 \%$ in weight of $\mathrm{Mag}-\mathrm{H}^{+}$which is previously dried for 30 minutes in the oven at $105^{\circ} \mathrm{C}$. The mixture is stirred for $6 \mathrm{~h}$ at room temperature $\left(25^{\circ} \mathrm{C}\right)$. Table 1 summarizes the effect of the amount of Mag- $\mathrm{H}^{+}$on the $\mathrm{Mn}$ of the obtained polymer (PLM), using various amount of Mag$\mathrm{H}^{+}(2,4,5,10,15,20$ and $25 \%$ by weight). The results of Table 1 show that $10 \%$ by weight of Mag- $\mathrm{H}^{+}$seems to limit the increase of molar masses $(\mathrm{Mn}=1360 \mathrm{~g} / \mathrm{mol})$. After $6 \mathrm{~h}$, the reaction mixture is dissolved in $\mathrm{CH}_{2} \mathrm{Cl}_{2}$, filtered and precipitated in cold methanol $\left(\mathrm{CH}_{3} \mathrm{OH}\right)$ then dried in vacuum overnight. The polymerization reaction of limonene is described in Scheme 1.

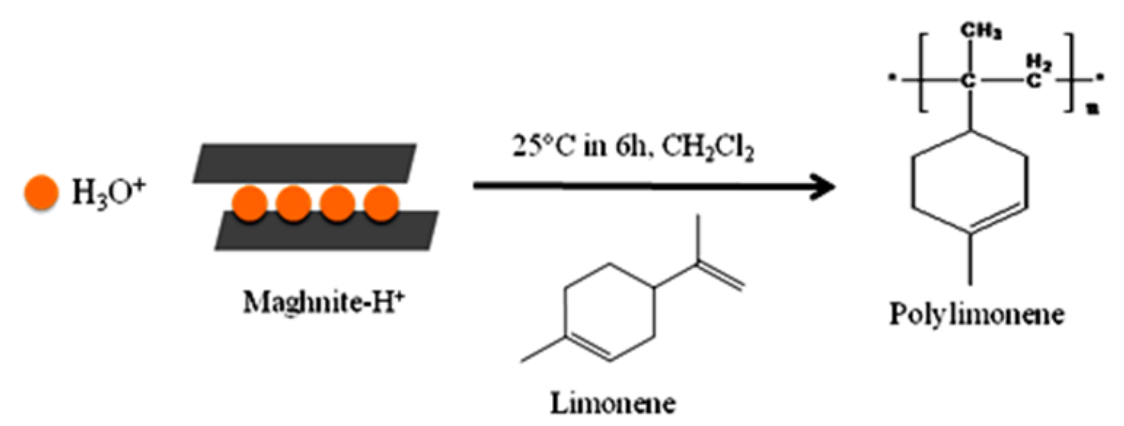

Scheme 1. Polymerization of Limonene catalyzed by Mag- $\mathrm{H}^{+}$. 
2.6 Synthesis of Nanocomposites Polylimonene/ Clay (PLM-Mag)

The synthesis of PLM-Mag nanocomposites was carried out by polymer and clay mixture method in solution. $0.5 \mathrm{~g}$ of the obtained polylimonene $(1360 \mathrm{~g} / \mathrm{mol})$ is dissolved in $25 \mathrm{~mL}$ of Dichloromethane $\left(\mathrm{CH}_{2} \mathrm{Cl}_{2}\right)$. The solution is then stirred for 15 minutes to completely dissolve

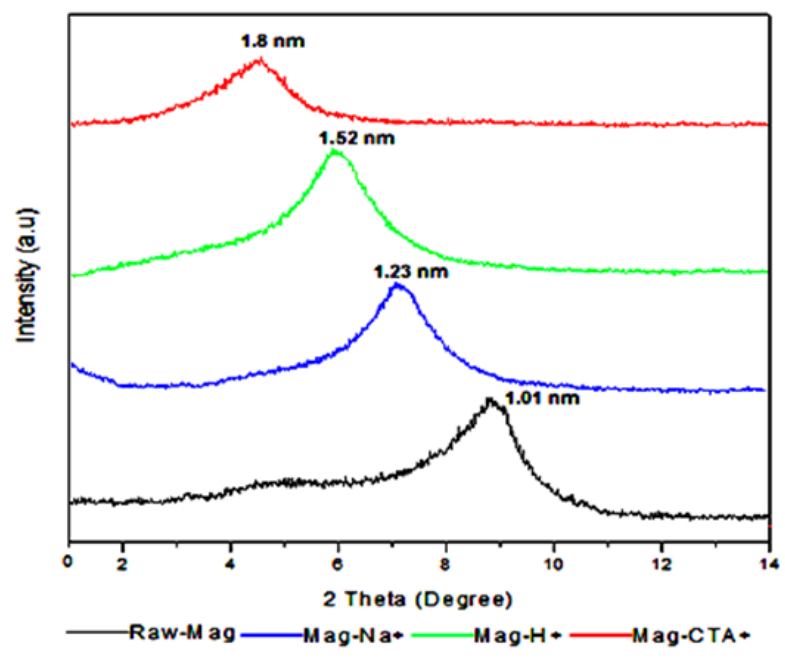

Figure 1. XRD patterns of Raw-Mag, Mag- $\mathrm{Na}^{+}$, Mag- $\mathrm{H}^{+}$and Mag-CTA ${ }^{+}$. the polylimonene. Subsequently, $2 \%$ by weight of the Mag- $\mathrm{CTA}^{+}$is added to the solution and then the mixture is treated by ultrasonicassisted method for 3 hours. The obtained nanocomposite is precipitated in methanol, filtered and dried under vacuum over night. The same procedure is repeated for different amounts of Mag-CTA ${ }^{+}: 3,6$, and $10 \%$ by weight to polylimonene (the synthesis of nanocomposites is described in Scheme 2). The obtained samples were named PLM-Mag (see experimental conditions in Table 2). The \% yield of the obtained polymer is calculated by a simple weighing according to the following equation:

$$
\text { Yield }(\%)=\left(M_{0} / M_{1}\right) \times 100 \%
$$

Where $M_{0}$ is weight of the obtained nanocomposites (PLM-Mag) and $\mathrm{M}_{1}$ denotes weight of the PLM and Mag-CTA+.

\section{Results and Discussion}

3.1 Characterization of Maghnite $\left(\mathrm{H}^{+}, \mathrm{Na}^{+}\right.$and $\mathrm{CTA}^{+}$)

X-Ray diffractograms of Raw-Mag, Mag- $\mathrm{H}^{+}$, Mag- $\mathrm{Na}^{+}$and Mag-CTA ${ }^{+}$are shown in Figure 1. The calculated basal spacing $\left(d_{001}\right)$ from XRD

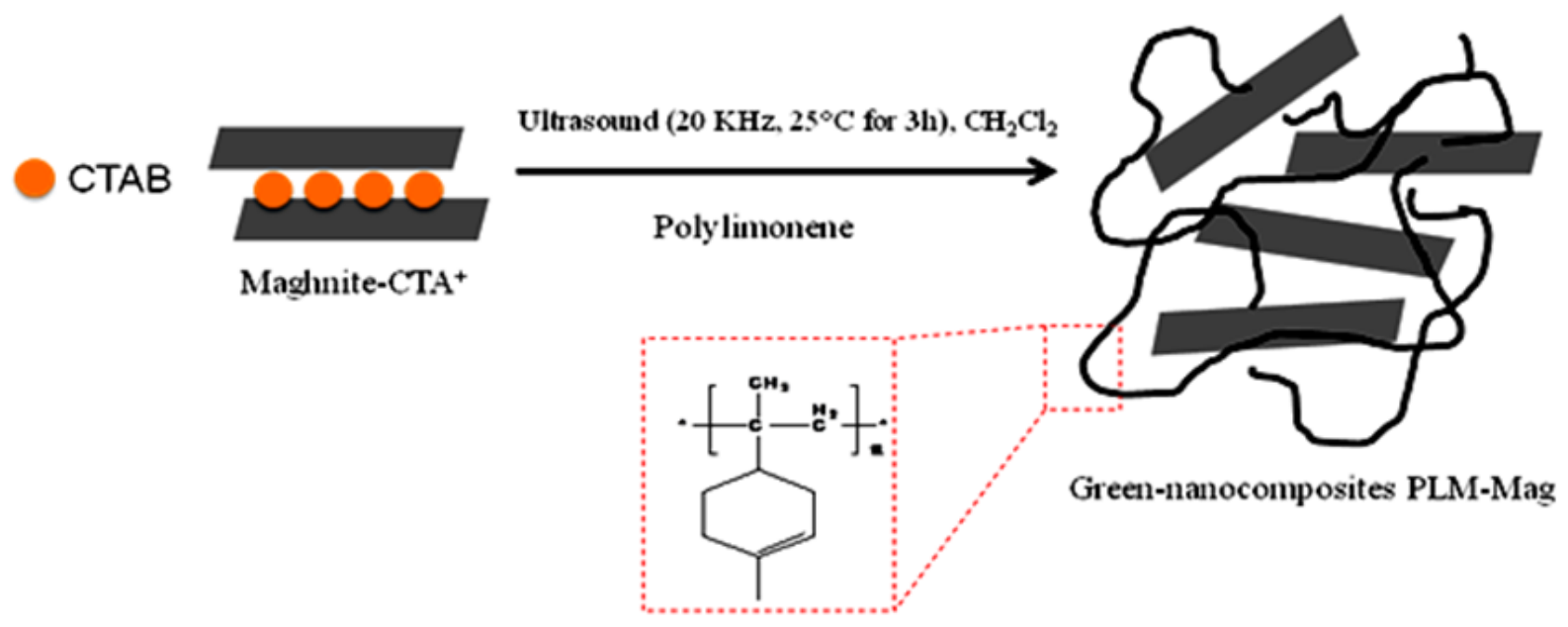

Scheme 2. Synthesis of nanocomposites (PLM-Mag) by ultrasonic irradiation.

Table 2. Experimental conditions for the preparation of nanocomposites PLM-Mag using Ultrasonification.

\begin{tabular}{lccccc}
\hline Samples & PLM $(\mathrm{g})$ & Time $(\mathrm{h})$ & Organo-clay $(\%)$ & Yield (\%) & Frequency $(\mathrm{kHz})$ \\
\hline PLM-Mag 2\% & 0.5 & 3 & 2 & 100 & 20 \\
PLM-Mag 3\% & 0.5 & 3 & 3 & 100 & 20 \\
PLM-Mag 4\% & 0.5 & 3 & 6 & 100 & 20 \\
PLM-Mag 10\% & 0.5 & 3 & 10 & 100 & 20 \\
\hline
\end{tabular}


patterns, applying Bragg equation $(2 d \sin \theta=$ $\mathrm{n} . \lambda$ ) is $1.01 \mathrm{~nm}$ for Raw-Mag and $1.52 \mathrm{~nm}$ for Mag- $\mathrm{H}^{+}$. This increase in basal spacing is explained by the substitution of single water between the sheet of Raw-Mag by two interlamellar water layer in $\mathrm{Mag}^{-\mathrm{H}^{+}}$(atomic radius of $\mathrm{H}_{3} \mathrm{O}^{+}=0.51 \mathrm{~nm}$ ). The diffractograms of Mag$\mathrm{Na}^{+}$and Mag-CTA ${ }^{+}$show that the interfoliar distance goes from $d=1.23 \mathrm{~nm}$ for the Mag- $\mathrm{Na}^{+}$ which corresponds to the exchange by $\mathrm{Na}^{+}$in the galleries of Maghnite (atomic radius of $\mathrm{Na}^{+}$ $=0.22 \mathrm{~nm}$ ) to $d=1.8 \mathrm{~nm}$ for the Mag-CTA ${ }^{+}$. This increase indicates that there is intercalation of the alkyl ammonium ions of the CTAB in the inter-foliar galleries and a cationic exchange of $\mathrm{Na}^{+}$by $\mathrm{CTA}^{+}$. The addition of the alkyl ammonium ions causes a displacement of the characteristic peak of the interfoliar distance of montmorillonite towards the weak

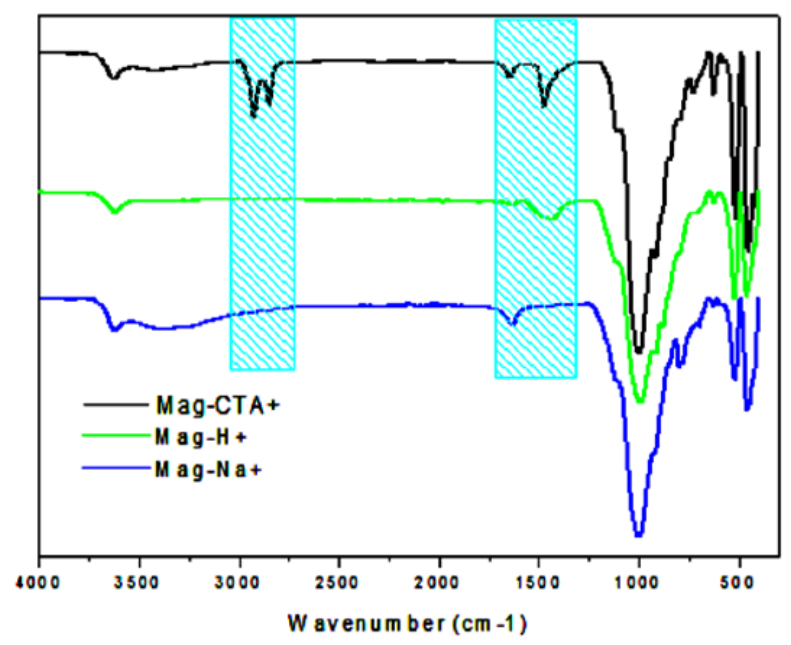

Figure 2. FT-IR spectra of Mag-CTA ${ }^{+}$, Mag$\mathrm{Na}^{+}$and Mag- $\mathrm{H}^{+}$.

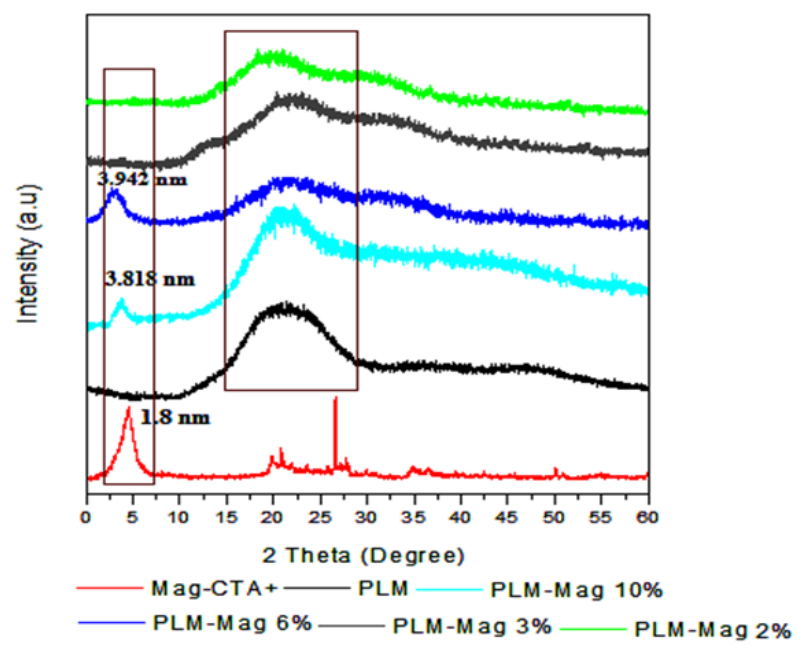

Figure 3. XRD patterns of the obtained nanocomposites PLM-Mag. nails (4.90 degree) for Mag-CTA+. These results show the effect of ultrasonic irradiation on the preparation of Mag-CTA ${ }^{+}$. Aicha Khenif et al. [25], obtained an interlayer distance of $1.98 \mathrm{~nm}$ during $24 \mathrm{~h}$ of stirring for the preparation of $\mathrm{CTAB} / \mathrm{Clay}$, in our case, an interlayer distance of $1.8 \mathrm{~nm}$ was obtained only in $1 \mathrm{~h}$.

The IR spectra (Figure 2) of the Mag- $\mathrm{H}^{+}$, Mag- $\mathrm{Na}^{+}$and Mag-CTA ${ }^{+}$show an intense peak at $1057 \mathrm{~cm}^{-1}$ and two bands at 455 and 515 $\mathrm{cm}^{-1}$ relating to the elongation vibrations, and torsion of the $\mathrm{Si}-\mathrm{O}-\mathrm{Si}$ and $\mathrm{Si}-\mathrm{O}-\mathrm{Al}$ bonds respectively [26,27]. The band at $1000 \mathrm{~cm}^{-1}$ due to the vibration of $\mathrm{Si}-\mathrm{O}$ of the Maghnite. The bands at 1643 and $3625 \mathrm{~cm}^{-1}$ are attributable to the extension of the hydroxyl groups of water bonded by hydrogen bond to clay [28]. Different bands were obtained after the modification of Maghnite by $\mathrm{CTA}^{+}$, two new bands were observed for Mag-CTA ${ }^{+}$, in the 2850 and 2922 $\mathrm{cm}^{-1}$ regions corresponding to the $\mathrm{C}-\mathrm{H}$ stretching vibrations of methyl group. The results obtained by FT-IR analysis show intercalation of the alkyl ammonium ions of the CTAB in the inter-foliar galleries and confirm the results obtained by XRD analysis.

3.2 Characterization of Nanocomposites (PLMMag)

The XRD patterns of the obtained polymer and nanocomposites (PLM and PLM-Mag) are shown in Figure 3. The XRD pattern of polylimonene (PLM) presents no peak confirming its amorphous structure. This amorphous structure is observed in the nanocomposites

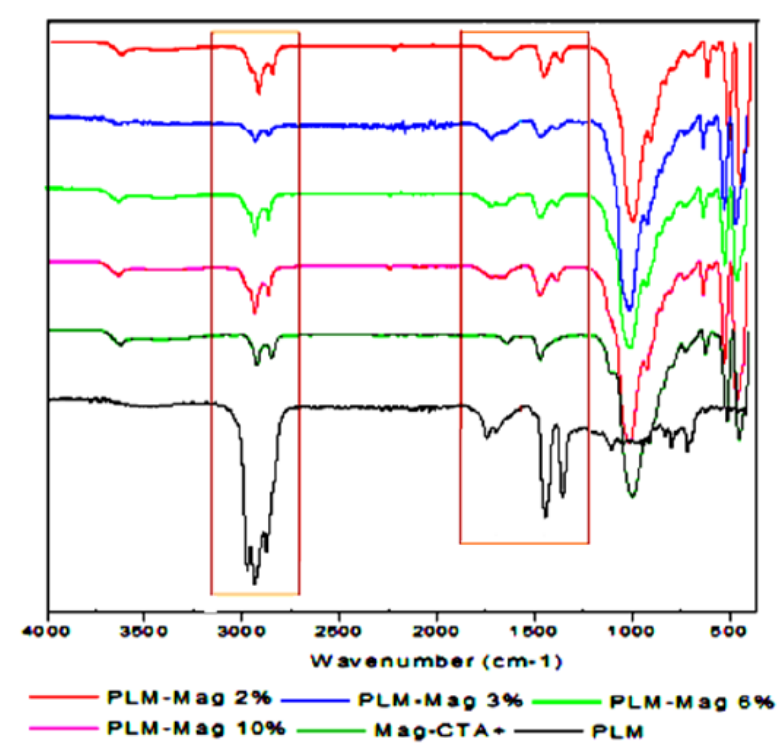

Figure 4. FT-IR spectrums of PLM and nanocomposites PLM-Mag. 
with the appearance of additional peak characteristic of $\mathrm{Mag}-\mathrm{CTA}^{+}$which confirms its good dispersion in the polymer matrix. The nanocomposites prepared by 6 and $10 \%$ by weight of Mag- $\mathrm{CTA}^{+}$showed a single peak around $2 \theta=3^{\circ}$ corresponding to the interlayer distances $\mathrm{d}_{001}=$ 3.942 and $3.818 \mathrm{~nm}$ respectively. The interlayer distance of these nanocomposites was increased more than twice compared to the Mag-CTA+, which had an interlayer distance of $1.8 \mathrm{~nm}$. This result also confirms that the obtained polylimonene were well intercalated between the clay galleries. Except for the case of nanocomposites obtained by 2 and $3 \%$ by weight of Mag-CTA ${ }^{+}$, the diffraction peak of Mag-CTA ${ }^{+}$is not observed, confirm the exfoliation of the
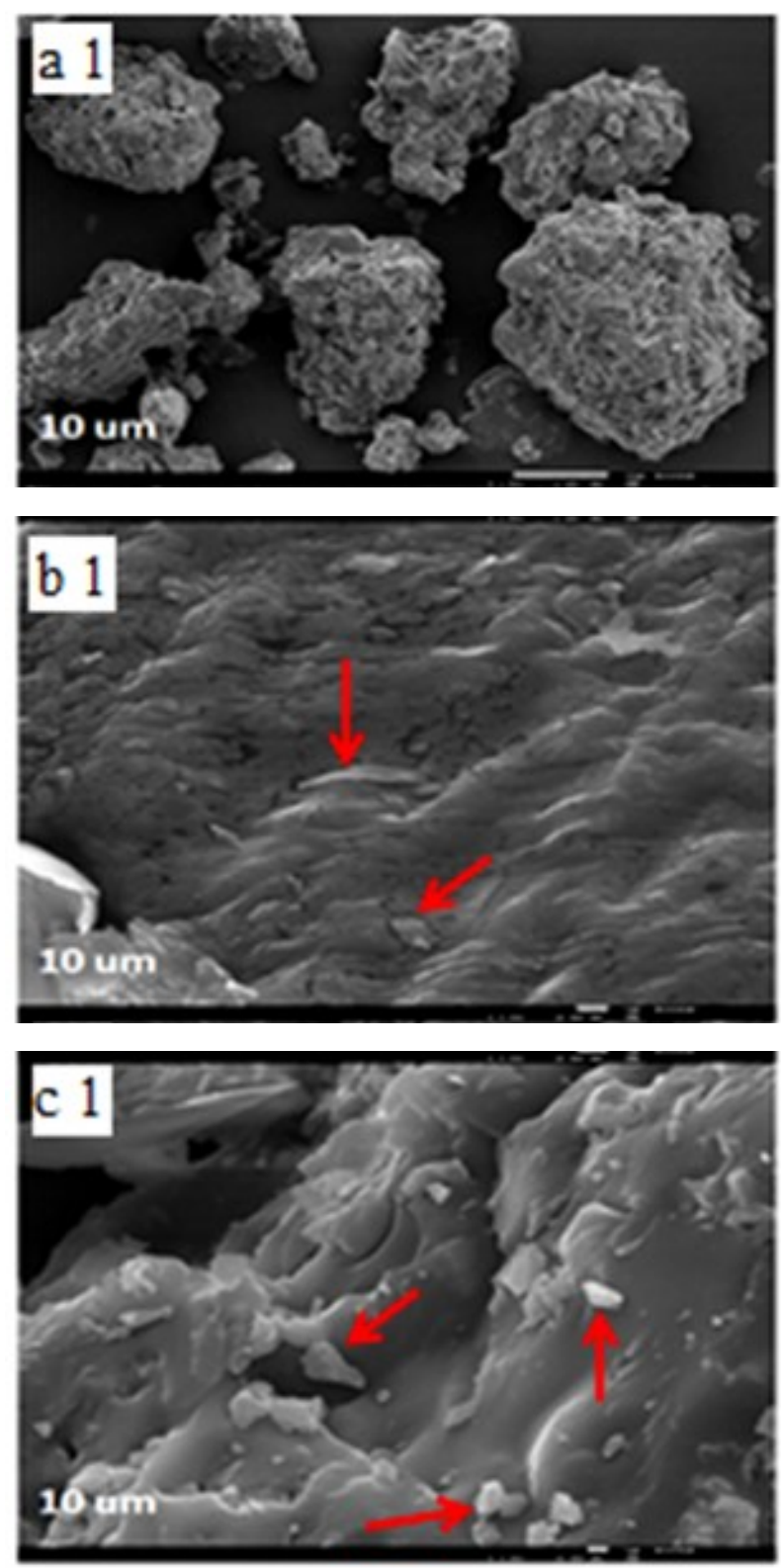

clay, which explains a good diffusion of the polylimonene in the clay galleries. These results are in agreement with those obtained by Hanène Salmi-Mani et al. [29]. The time of the ultrasound treatment $(3 \mathrm{~h})$ is a key factor that can cause a formation of exfoliated nanocomposites [19]. When the cavitation bubbles reach a critical size, it can implode violently within the reaction medium, thus releasing large amounts of energy. This behavior leads to a large dispersion of the clay sheets in the PLM matrix. It can be noted that the use of ultrasound for the synthesis of nanocomposites has a great advantage compared with classic methods which is take $24 \mathrm{~h}$ of reaction time [30].

The infrared spectra of the nanocomposites
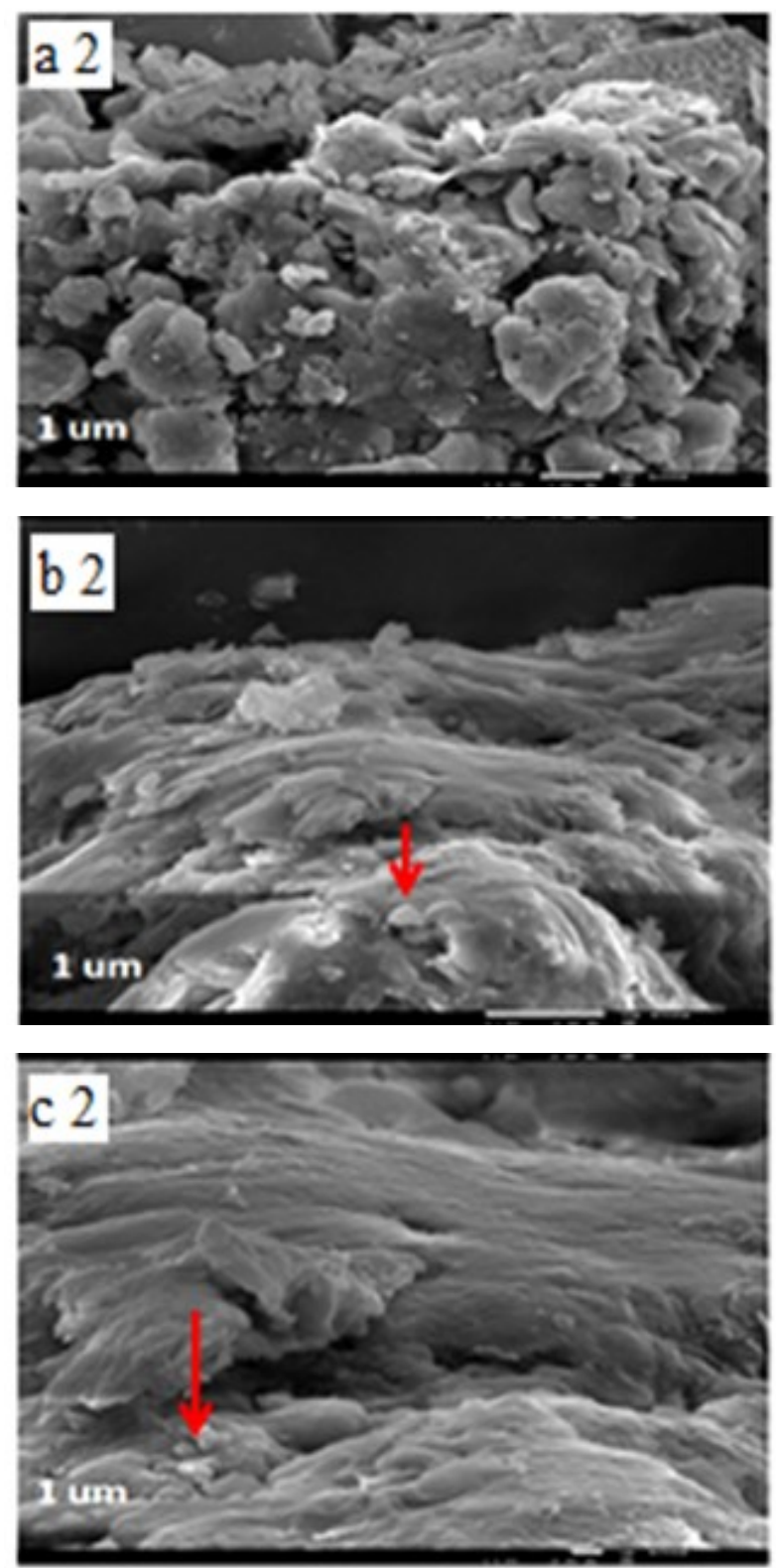

Figure 5. SEM images of Mag-CTA+ (a1 and a2), PLM-Mag 10\% (b1 and b2) and PLM-Mag 2\% (c1 and $\mathrm{c} 2)$. 
(PLM-Mag 2, 3, 6 and 10\%) and polylimonene (PLM) are shown in Figure 4. The infrared spectra show that the polylimonene and the nanocomposites have almost the same vibration bands overlapping with the vibration bands of the organo-modified clay $\left(\mathrm{Mag}-\mathrm{CTA}^{+}\right)$ and the FT-IR spectra show that the obtained nanocomposites PLM-Mag are in a good agreement with the polylimonene structure. The adsorption band at $1673 \mathrm{~cm}^{-1}$ corresponds to the double bond $\mathrm{C}=\mathrm{C}$ in the polylimonene was observed in the FT-IR spectra of the obtained nanocomposites. The $\mathrm{C}-\mathrm{H}$ symmetry and asymmetry stretching of the methyl and methylene group was observed at 2922 and $2935 \mathrm{~cm}^{-1}$. These results confirm the interaction of the functional group of PLM with the internal surface of clay. Compare to the FT-IR spectrum of the pure PLM, the spectra of the obtained nanocomposites show the appearance of the intense peak at $1000 \mathrm{~cm}^{-1}$ corresponding to the
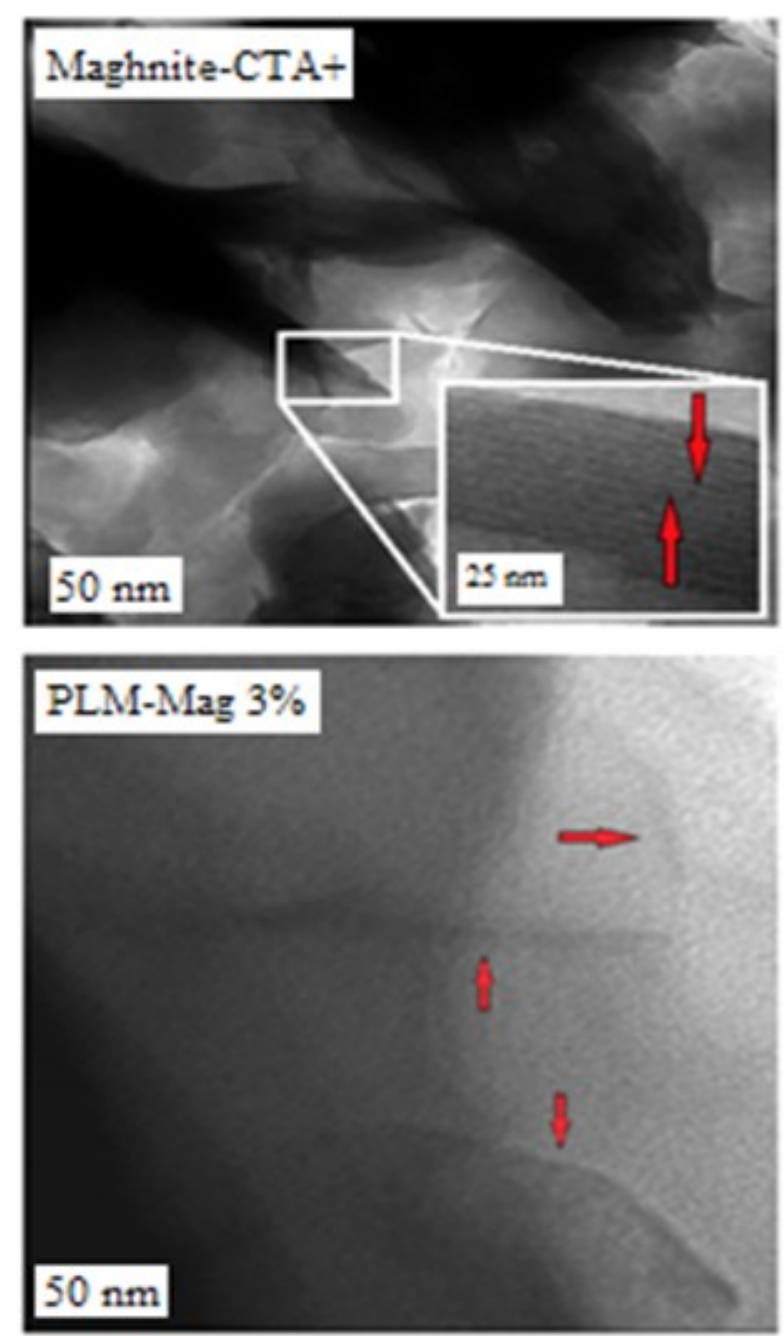

vibration of $\mathrm{Si}-\mathrm{O}$ of the Mag-CTA+. However, the absorption bands observed on the FT-IR spectra of pure PLM and Mag- $\mathrm{CTA}^{+}$are gathered on the FT-IR spectra of the obtained nanocomposites. These results show the intercalation of polylimonene in the interlayer montmorillonite gallery.

Figure 5 shows the SEM images of the organo-modified clay (Mag- $\mathrm{CTA}^{+}$), the intercalated nanocomposites (PLM-Mag 10\%) and the exfoliated nanocomposites (PLM-Mag 2\%). The comparison of the $\mathrm{Mag}-\mathrm{CTA}^{+}$morphology (Figure 5 a1 and a2) with the first nanocomposites PLM-Mag 10\% (Figure 5 b1 and b2) shows a more organized small particle structure of montmorillonite. In the nanocomposites PLM-Mag 2\% (Figure $5 \mathrm{c} 1$ ), the observation of nanocomposites at $10 \mu \mathrm{m}$ reveals a formation of montmorillonite plate separated, that is a partial exfoliation, the same sample observed at $1 \mu \mathrm{m}$ (Figure $5 \mathrm{c} 2$ ), shows a rougher surface
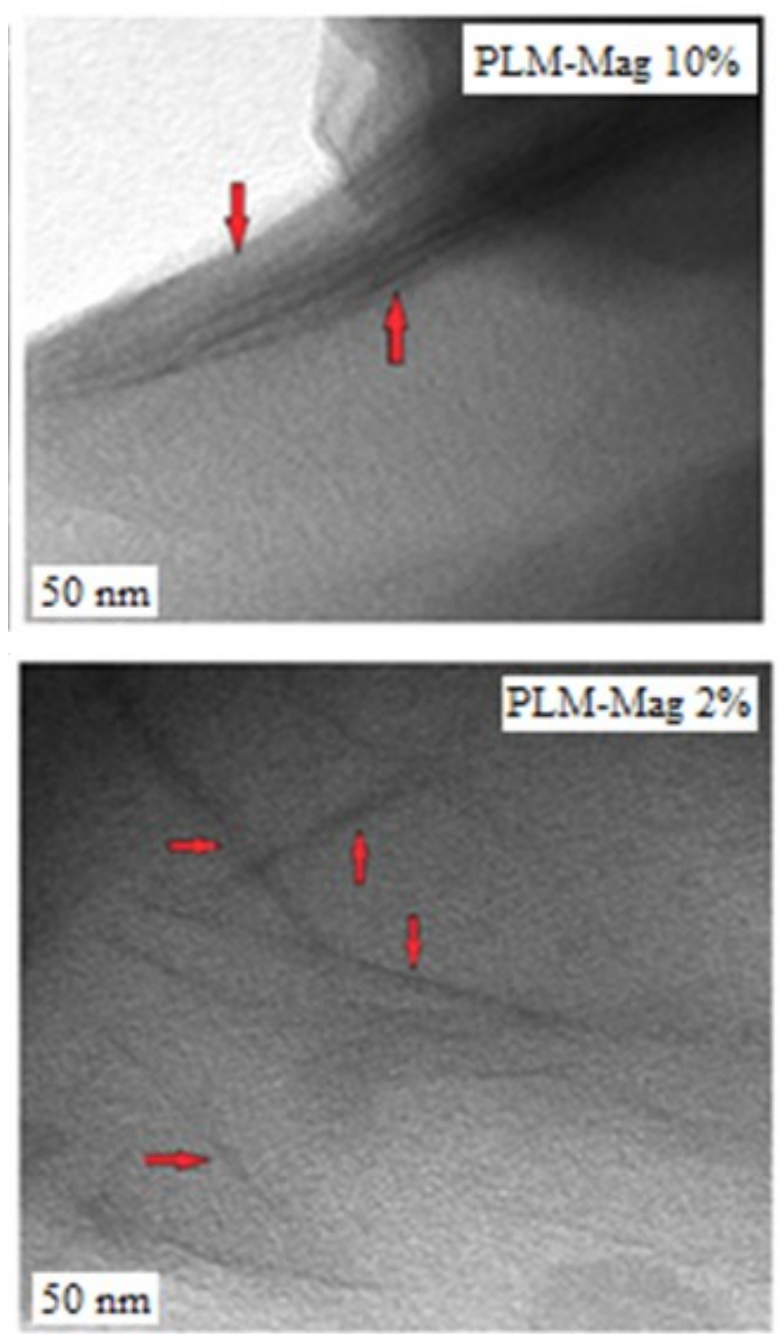

Figure 6. TEM images of Mag-CTA ${ }^{+}$, PLM-Mag 10\% (intercalated), PLM-Mag 3\% (exfoliated) and PLM-Mag 2\% (exfoliated). 
and a covering of the montmorillonite surface by the polylimonene.

The transmission electron microscopy was used to determine the dispersion of Mag-CTA ${ }^{+}$ in polylimonene matrix and also to compare the results obtained by the XRD analysis. The TEM images of Mag-CTA ${ }^{+}$and the obtained nanocomposites PLM-Mag (2, 3, and 10\%) are shown in Figure 6. For Mag-CTA ${ }^{+}$, it is easy to define the silicate layers by the dark and bright lines. The nanocomposite (PLM-Mag 10\%) prepared by $10 \%$ of Maghnite-CTA ${ }^{+}$shows an intercalated structure of the modified clay. However, the nanocomposites (PLM-Mag 2 and 3\%) show a partial or total exfoliated structure and the clay nanoparticles are mainly well dispersed in the polylimonene matrix. These results confirm the results obtained by XRD analysis. This also explains the beneficial effect of ultrasound on the dispersion of clay in the PLM matrix. The effect of ultrasound also gives better yields compared to the in-situ polymerization synthesis method [30].

Thermogravimetric analysis was carried out under nitrogen with a heating rate of 20 ${ }^{\circ} \mathrm{C} / \mathrm{min}$. Figure 7 shows the TGA curves of pure polylimonene and that of nanocomposites of 2 , 3,6 , and $10 \%$ by weight of Mag-CTA ${ }^{+}$. It can be seen that the pure polylimonene and all its nanocomposites exhibit a one-step weight loss mechanism. The nanocomposites show a high thermal stability up to a degradation temperature of $200-250{ }^{\circ} \mathrm{C}$, while the degradation temperature of pure polylimonene observed about $140{ }^{\circ} \mathrm{C}$. In addition, the intercalated nanocomposites (PLM-Mag $10 \%$ ) prepared with $10 \%$ of Mag-CTA ${ }^{+}$showed highest thermal stability with a degradation temperature of $250{ }^{\circ} \mathrm{C}$. These results show that the thermal stability of

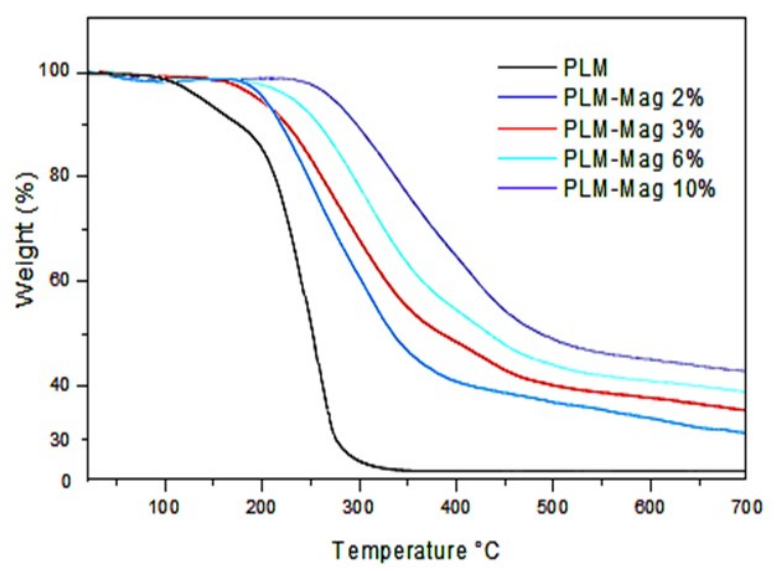

Figure 7. TGA curves of PLM and PLM-Mag $(2,3,6$, and $10 \%)$. the obtained nanocomposites is not only related to the clay content, but it is also much more related to the state of the clay in the polymeric matrix, it is related to the surface area between the polymeric matrix and the clay. This gain in thermal stability is due, according to previous work [31], to the formation of a protective carbonized layer. The formation of this layer is favored by the fine dispersion of intercalated or exfoliated particles of montmorillonite which play an inorganic support role [32]. In general, the degradation temperature of the polymers is increased after the incorporation of exfoliated lamellar silicates [33-35], which values these polymers and allows their use at higher temperatures.

\section{Conclusion}

The effect of organo-modified clay (Mag$\mathrm{CTA}^{+}$), prepared and used with different ratios, on the nanocomposites polylimonene/Maghnite properties is studied. The XRD results indicate that the nanocomposites prepared with 2 and 3 \%wt of $\mathrm{Mag}^{-\mathrm{CTA}^{+}}$were exfoliated, and the nanocomposites prepared with 6 and $10 \% \mathrm{wt}$ of Mag- $\mathrm{CTA}^{+}$were intercalated, leading to an expansion of the interlayer distance between the layers. Thermogravimetric results indicate that the nanocomposites present a high thermal stability compare to the pure polylimonene $\left(\mathrm{T}<250^{\circ} \mathrm{C}\right)$. This is attributed to the interactions between all the polymer chains and the organic compounds of the modified clay. The reinforcing effect of the clay in the polymer is confirmed by increasing the rigidity of the system. The morphology study by SEM and TEM of the obtained nanocomposites confirmed an organization of certain particles, and in other cases a separation in plates made up of montmorillonite layers. This confirms partial or total exfoliation of montmorillonite in the polymer matrix and formation of the nanocomposites. In general, the data show that CTAB is effective for the preparation of organophylic clay.

\section{Acknowledgments}

We would like to thank the (DGRSDT) $D i$ rection Générale de la Recherche Scientifique et du Développement Technologique-Algeria, and the CDRSP-IP Leiria (Centre For Rapid and Sustainable Product Development) for giving us access to their STA device. We also would like to thank Dr A. Zaoui for help and advices through all the writing process.

\section{References}


[1] Kojima, Y., Usuki, A., Kawasumi, M., Okada, A., Ukushima, Y.F., Kamigaito, O. (1993). Mechanical properties of nylon 6 -clay hybrid. $J$. Mater. Res., 8, 1185-1189.

[2] Harrane, A., Meghabar, R., Belbachir, M. (2006). In situ polymerization of $\varepsilon$ caprolactone catalyzed by Maghnite TOA to produce $\operatorname{poly}(\varepsilon$-caprolactone)/ montmorillonite nanocomposites. Des. Mono. And Polym., 9, 181-191.

[3] Zare, Y., Fasihi, M., Rhee, K.Y. (2017). Efficiency of stress transfer between polymer matrix and nanoplatelets in clay/polymer nanocomposites. Appl. Clay. Sci., 143, 265-272.

[4] Kotal, M., Bhowmick, A.K. (2015). Polymer nanocomposites from modified clays: Recent advances and challenges. Pro. Polym. Sci., 51, $127-187$.

[5] Mykola, S., Olga, N., Dmitry, M. (2016). The influence of alkylammonium modified clays on the fungal resistance and biodeterioration of epoxy-clay nanocomposites. Int. Biodeterior. Biodegrad., 110, 136-140.

[6] Sun, J. (2007). D-Limonene: Safety and Clinical Applications. Alter. Med. Rev., 12, 259-264.

[7] Rukel, E., Wojcik, R., Arlt, H. (1976). Cationic Polymerization of a-Pinene Oxide and BPinene Oxide by a Unique Oxonium lonCarbenium Ion Sequence. J. Macromol. Sci. Part A., 10, 1371-1390.

[8] Sharma, S., Srivastava, A.K. (2004). Synthesis and characterization of copolymers of limonene with styrene initiated by azobisisobutyronitrile. Eur. Polym. J., 40, 2235-2240.

[9] Roberts, W., Day, A. (1950). A Study of the Polymerization of $\alpha^{-}$and B-Pinene with Friedel- Crafts Type Catalysts. J. Amer. Chem. Soci., 72, 1226-1230.

[10] Modena, M., Bates, R.B., Marvel, S.C. (1965). Some low molecular weight polymers of d-limonene and related terpenes obtained by Ziegler-type catalysts. J. Polym. Sci. Part A Gen Pap., 3, 949-960.

[11] Barros, M.T., Petrova, K.T., Ramos, A.M. (2007). Potentially Biodegradable Polymers based on a- or B-Pinene and Sugar Derivatives or Styrene, Obtained under Normal Conditions and Microwave Irradiation. Eur. J. Org. Chem., 8, 1357-1363.

[12] Mathers, R.T., Damodaran, K. (2007). Renewable Chain Transfer Agents for Metallocene Polymerizations: The Effects of Chiral Monoterpenes on the Polyolefin Molecular Weight and Isotacticity. J. Polym. Sci. Part A Polym. Chem., 45, 3150-3165.

[13] Bhanvase, B.A., Pinjari, D.V., Gogate, P.R.,
Sonawane, S.H., Pandit, A.B. (2011). Process intensification of encapsulation of functionalized $\mathrm{CaCO} 3$ nanoparticles using ultrasound assisted emulsion polymerization. Chem. Eng. Proce., 50, 1160-1168.

[14] Bhanvase, B.A., Pinjari, D.V., Gogate, P.R., Sonawane, S.H., Pandit, A.B. (2012). Synthesis of exfoliated poly(styrene-co-methyl methacrylate)/montmorillonite nanocomposite using ultrasound assisted in situ emulsion copolymerization. Chem. Eng. J., 181, 770-778.

[15] Bhanvase, B.A., Pinjari, D.V., Gogate, P.R., Sonawane, S.H., Pandit, A.B. (2012) Analysis of semibatch emulsion polymerization: Role of ultrasound and initiator. Ultrason. Sonochem., 19, 97-103.

[16] Bhanvase, B.A., Sonawane, S.H., Pinjari, D.V., Gogate, P.R., Pandit, A.B. (2014). Kinetic studies of semibatch emulsion copolymerization of methyl methacrylate and styrene in the presence of high intensity ultrasound and initiator. Chem. Eng. Proce. Process Intensification, 85, 168-177.

[17] Bhanvase, B.A., Sonawane, S.H. (2014). Ultrasound Assisted In-Situ Emulsion Polymerization for Polymer Nanocomposite: A Review. Chem. Eng. Proce. Process Intensification, 85, 86-107.

[18] Yusof, N.S.M., Babgi, B., Alghamdi, Y., Aksu, M., Madhavan, J., Ashokkumar, M. (2016). Physical and chemical effects of acoustic cavitation in selected ultrasonic cleaning applications. Ultrason. Sonochem., 29, 568-576.

[19] Cherifi, Z., Boukoussa, B., Zaoui, A., Belbachir, M., Meghabar, R. (2018). Structural, morphological and thermal properties of nanocomposites poly(GMA)/clay prepared by ultrasound and in-situ polymerization. Ultrason. Sonochem., 48, 188-198.

[20] Derdar, H., Mitchell, G.R., Mahendra, V.S., Benachour, M., Haoue, S., Cherifi, Z., Bachari, K., Harrane, A., Meghabar, R. (2020). Green Nanocomposites from Rosin-Limonene Copolymer and Algerian Clay. Polymers, 12, 1971.

[21] Derdar, H., Belbachir, M., Hennaoui, F., Akeb, M., Harrane, A. (2018). Green copolymerization of limonene with B-pinene catalyzed by an eco-catalyst Maghnite- $\mathrm{H}^{+}$. Polym. Sci. Ser. B., 60, 555-562.

[22] Embarek, N., Sahli, N. (2020). A Novel Green Synthesis Method of Poly (3Glycidoxypropyltrimethoxysilane) Catalyzed by Treated Bentonite. Bull. Chem. React. Eng. Catal., 15, 290-303.

[23] Haoue, S., Derdar, H., Belbachir, M., Harrane, A. (2020). Polymerization of ethylene glycol dimethacrylate (EGDM), using an Al- 
gerian clay as eco-catalyst (maghnite- $\mathrm{H}^{+}$and Maghnite-Na+). Bull. Chem. React. Eng. Catal., 15, 221-230.

[24] Derdar, H., Belbachir, M., Harrane, A. (2019). A green synthesis of polylimonene using Maghnite- $\mathrm{H}^{+}$, an exchanged montmorillonite clay, as eco-catalyst. Bull. Chem. React. Eng. Catal., 14, 69-79.

[25] Khenifi, A., Zohra, B., Kahina, B., Houari, H., Zoubir, D. (2009). Removal of 2,4- DCP from wastewater by $\mathrm{CTAB} /$ bentonite using onestep and two-step methods: A comparative study. Chem. Eng. J., 146, 345-354.

[26] Cicel, B. (1992). Mineralogical composition and distribution of $\mathrm{Si}, \mathrm{Al}, \mathrm{Fe}, \mathrm{Mg}$ and $\mathrm{Ca}$ in the fine fractions of some Czech and Slovak bentonites. Geologica. Carpath. Ser. Clays., 43, 3-7.

[27] Grenier, A., Wendorff, J.H. (2007). Electrospinning: A Fascinating Method for the Preparation of Ultrathin Fibers. Angewandte Chemie International Edition, 46, 5670-5703.

[28] Hrachova, J., Madejova, J., Billik, P., Komadel, P., Fajnor, S.V. (2007). Dry grinding of Ca and octadecyltrimethylammonium montmorillonite. J. Coll. Interf. Sci., 316, 589-595.

[29] Salmi-Mani, H., Ait-Touchente, Z., Lamouri,
A., Carbonnier, B., Caron, J.F., Benzarti, K., Chehimi, M.M. (2016). Diazonium salt-based photoiniferter as a new efficient pathway to clay-polymer nanocomposites. RSC $A d v ., 6$, 88126.

[30] Embarek, N., Sahli, N., Belbachir, M. (2019). Preparation and characterization of poly(3glycidoxypropyltrimethoxysilane) nanocomposite using organophilic montmorillonite clay (Mag-cetyltrimethylammonium). J. Compos. Mater. 53: 4313-4322.

[31] Bureau, M.N., Denault, J., Cole, K.C., Enright, G.D. (2002). The role of crystallinity and reinforcement in the mechanical behavior of polyamide-6/ clay nanocomposites. Polym. Eng. sci., 42, 1897-1906.

[32] Kherroub, D.E., Belbachir, M., Lamouri, S. (2014). Nylon 6/clay nanocomposites prepared with Algerian modified clay (12-maghnite). Res. Chem. Int., 41, 5217-5228.

[33] Vaia, R.A., Price, G., Ruth, P.N., Nguyen, H.T., Lichtenhan, J. (1999). Polymer/layered silicate nanocomposite as high performance ablative materials. Appl. Clay Sci., 15, 67-92. 